Est Ag 47 (2012) 535-552

\title{
De la Teología a la Psicología, y vuelta
}

\author{
TOMÁs MARCos MARTíneZ*
}

RESUMEN: Todas las ciencias están interconectadas. No sólo se aúnan en sus pretensiones de apresar la realidad: cómo funciona, a qué lleva, qué significa; sino que también coinciden en sus prestaciones utilitarias: mejorar y proteger la vida humana. Además proceden unas de otras, aunque no lo parezca, igual le pasa al hombre con la ameba. Ciencias aparentemente dispares, para algunos contrarias, como la teología y la psicología, o no son más que parientes mal avenidos o usando ropajes distintos les delatan idénticas facciones.

PALABRAS CLAVE: Filosofía, teología, ciencias, psicología, virtudes.

ABSTRACT: All sciences are connected. Allied not only in its claims of capturing the reality: how it works, where it leads, what it means; but also agree in their utilitarian benefits: improve and protect human life. Moreover derived from each other, although it does not seem so, the same happens between the man and the amoeba. Seemingly disparate sciences, contraries to some, like theology and psychology, or are but ill-assorted relatives or using different clothes betray them identical features.

KEY WORDS: Philosophy, theology, sciences, psychology, virtues.

\footnotetext{
1 Este artículo, ligeramente retocado, ha sido publicado online para un curso de Formación Continua de la Vida Religiosa: www.agustinos-es.org/FVR/forcont

* Estudio Teológico Agustiniano, Valladolid
} 


\section{Madres e hijas}

Se ha dicho de la filosofía que es la "madre de las ciencias"1. Tal vez suene un poco petulante a los científicos perdonavidas de hoy día, pero es una afirmación que tiene toda la razón del mundo. Solemos entender ciencia en su sentido más amplio como un saber comprobado, una scientia ('conocimiento' en latín) que ofrece seguridad, objetivo, común, distinguido de la opinión en cuanto saber subjetivo, anecdótico o inseguro. Ya lo diferenciaba Platón: "opinar sin poder fundamentarlo no es ciencia"2. De modo que cuando comentamos: 'si te coge un chaparrón en la calle, pillarás un resfriado', lo tomamos como una verdad integrada colectivamente; mientras que si oímos: 'me cayó un aguacero terrible, pero al día siguiente saqué el permiso de conducir tan campante', asumimos que es una excepción individual.

Estrictamente hablando, la ciencia comienza con la filosofía, cuando algunos griegos extravagantes del siglo $\mathrm{VI} \mathrm{aC}$ tales como Tales empiezan a buscar el elemento más simple del universo, por ejemplo el agua o el aire o el fuego o la tierra, para explicar las cosas y sucesos de la naturaleza como variación o combinaciones de aquéllos. Llegarán así a conclusiones extrañas, tirando a absurdas, como que "los vientos surgen cuando el aire se ha condensado y se mueve a sus impulsos, al concentrarse y hacerse más espeso da lugar a las nubes y así se torna en agua, cuando el agua caída de las nubes se solidifica se produce el granizo, (...) y el relámpago cuando las nubes se abren por la violencia de los vientos"3. ¡Qué modo de disparatar! ¡Pero si todo el mundo sabe que rayos, truenos y centellas provienen de Zeus, el dios del cielo y la tormenta!

La filosofía griega de la naturaleza fue una explicación inmanente de las cosas. Buscaba las causas de todo lo que sucedía en el mundo en leyes internas, físicas. Y ese será el nacimiento de la ciencia, el saber comprobado inmanentemente, pues no hay otro modo de hacer una comprobación cierta. El saber colectivo puede ser después de todo sólo una opinión y no un saber objetivo, una ciencia real. Ese fue el descubrimiento que hizo la filosofía y en el que se hizo a sí misma. Desde los primeros momentos, esta forma de conocimiento tomará dos variantes para hacer el control probatorio. Una será empírica: partir de lo que muestran los sentidos para llegar a conclusiones generales (inducción); y otra racional: comenzar con lo que

\footnotetext{
1 J. FerRater Mora, Diccionario de Filosofía, 1, Madrid 1981, 491.

2 Banquete $202 \mathrm{a}$.

3 ANAXÍmEnes, Fragmentos 7.
} 
evidencia la razón para aplicarlo a casos concretos (deducción). Aunque son distintos, no son opuestos, en realidad se enredan y alimentan constantemente: la múltiple información sensorial hay que resumirla en conceptos para ordenarla, y como no se pueden abarcar todos los hechos particulares hay que suponerles principios universales, pero éstos se sustentan solo en experiencias perceptibles... El famoso silogismo: 'todos los hombres son mortales, Juan es un hombre, luego Juan es mortal' tiene sostén tanto empírico como racional.

Ahora bien, para llegar a la filosofía fue necesario un recorrido anterior. En él se encontraba una explicación trascendente de las cosas, pues era la deducción más simple, basada en la evidencia de la intuición: montes, nieves y flores tienen que venir de espíritus supremos, de dioses, ¡de dónde si no! No era tan fácil colegir concatenadamente que la tempestad y el diluvio procedían del agua terrena evaporada por el calor, condensada en nubes por el fresco, desatada en lluvia o granizo por el frío. Era más sencillo, más directo, más universal, concluir que el dios supremo del cielo decidía calores y aguaceros, ya fuera el Indra védico, el $\mathrm{Ra}$ de los egipcios, el Júpiter romano, el Thor de los germanos, el Inti de los incas.

Así que la teología fue la madre de la madre de las ciencias (sí, sí, la abuela), no hubiera sido posible el saber inmanente filosófico sin el saber trascendente teológico. La teología comienza siendo mitología, pero entendida ésta en su sentido originario y literal: narración (múthos) explicativa (lógos), y no en su sentido posterior y coloquial de leyenda, cuento chino. La mitología será así la primera interpretación global del universo, la primera (pre) [sic] ciencia común, el primer saber comprobado colectivamente, en el que todos estaban de acuerdo a falta de una teorización mejor de la realidad.

A fuer de lógica, la filosofía fue desdeñando las narraciones para volcarse en los argumentos. Sí, la mitología confecciona relatos mientras la filosofía entrelaza inferencias, aquélla toca las emociones mientras ésta se apoya en razones. Pero se interrogan mismamente sobre las cuestiones centrales del ser humano: por qué la vida y la muerte, la enfermedad y el dolor, la dicha y el mal, el odio y el amor. Los mitos lo hacen contando historias de dioses, héroes y hombres, que sugieren respuestas a las preguntas de partida: conseguida la planta de la vida tras mucho trasiego Gilgamesh se duerme exhausto y una serpiente se la birla (la inmortalidad humana es un deseo imposible), Adán y Eva contravinieron las normas divinas y fueron desterrados (la existencia es un valle de lágrimas, una expulsión del paraíso), Caín mató a su hermano Abel por envidia (el homicidio es un fratricidio rencoroso), Prometeo robó el fuego a Zeus para dárselo a los humanos (el progreso acerca a los hombres a los dioses). 


\section{Dos hermanas}

La filosofía griega se fue emancipando de la mitología, ni siquiera se consideró su hija natural, desconfió de ella acusándola de "decir muchas mentiras" 4 licencias poéticas incontrastables racionalmente. Pero encontró un alma gemela en la teología argumentativa, hija semejante aunque adusta de la mitología, que buscaba el fundamento trascendente del ser, pero sin cuentos, sólo con deducciones. Sería así la hermana mayor, una suerte de "filosofía teológica", verdaderamente "la ciencia primera"5. Ambas podrían crecer amistosamente, aprender una de la otra, aunque de vez en cuando discutieran, justamente como buenas hermanas. La teología le daba la mano cuando la filosofía se esmorraba en la oscuridad, la ayudaba a guiarse cuando la luz de la razón menguaba y apenas se podía ver, y por su parte la filosofía socorría a la teología cuando ésta se hundía en la superstición y el fanatismo, la sacaba del lodo de la credulidad y la crueldad. Así, Heráclito rechazó como contradictorio realizar sacrificios sangrientos para purificar delitos de sangre, Platón se nutrió de la religiosidad oriental de la inmortalidad del alma, los estoicos asumieron el mundo como un orden divino al tiempo inmanente al hombre (alma) y trascendente a él (providencia).

El cristianismo consolidó esta familia de hermanas al acoger y alimentar filosofía y teología con igual respeto. "Lo que de Dios se puede conocer está en los hombres manifiesto, (...) pues lo invisible de Dios, desde la creación del mundo, se deja ver a la inteligencia a través de sus obras" (Rm 1,19s). Los Padres de la Iglesia siguieron fomentando en el primer milenio la intimidad entre ambas. Pensaban que la filosofía griega era tan buena porque se había inspirado en los profetas hebreos ${ }^{6}$. Por supuesto que realzan la superioridad de la revelación sobre la razón, faltaría más, la verdad de Dios sobre la verdad humana, pero lo hacen en general de modo que la segunda no sea rebajada ni discriminada, sino asociada fraternalmente a los rasgos de la primera. Como dijo san Agustín: "entiende para creer, cree para entender"?.

La teología escolástica del segundo milenio, aunque pueda parecer sorprendente, todavía igualó más la fe y la razón. Anselmo de Canterbury definió la teología como "la fe que busca entenderse", con lo que ya no será posible acercarse a una sin toparse con la otra. Y Tomás de Aquino

\footnotetext{
${ }^{4}$ ARISTÓTELes, Metafísica 983a.

5 Ibidem 1026a.

6 SAN Justino, Apología 1,59s.

${ }^{7}$ Sermones 43,9 .

8 Proslogion, proemio.
} 
percibió que filosofía y teología eran como dos mapas para ayudar al hombre a comprender su territorio existencial; dibujan líneas y gráficos distintos y autónomos, sí, pero como persiguen el mismo horizonte no pueden divergir mucho, una sola es la meta. En caso de contradecirse, una de las dos estará equivocada, la filosofía claro, pues la teología es una "ciencia subalternada a una ciencia superior, la ciencia de Dios" o revelación", que es el saber máximo. En cualquier forma, teología y filosofía lo comparten prácticamente todo: destino (la verdad), camino (el razonamiento) y foro (la universidad).

La universidad fue inventada precisamente, a finales del siglo XII, para consolidar la teología desde la filosofía. Se la llamó universitas, 'colectividad', porque juntaba alumnos, profesores y saberes en un mismo espacio. La Iglesia había quedado como depositaria de la cultura clásica tras la devastación de los bárbaros, y estableció para trasmitirla junto a la doctrina cristiana escuelas monásticas y catedralicias. En ellas se impartía un compendio de la filosofía antigua, denominado artes liberales, propias de hombres libres, en oposición a las artes serviles o manuales. Comenzaba con el trivium ('vía de tres'): gramática (el sentido de las palabras), retórica (saber escribir y hablar) y dialéctica (la argumentación lógica), muy del gusto de la tradición latina; y seguía con el quadrivium ('vía de cuatro'): aritmética (números y operaciones), geometría (cálculo espacial), astronomía (los astros y el calendario) y música (canto e instrumentación), que remontaba a los pitagóricos. ¿Qué hace la música en la zona matemática en vez de en la literaria? Era como un gozne, no sólo implicaba voz y poesía sino también ritmo y proporción (escalas).

Aunque con gran variedad y variabilidad, la enseñanza en la facultas ('capacitación') de Artes (luego filosofía) duraba unos seis años, comenzando hacia los catorce de edad, tres para el gradus ('nivel') trivial o elemental (bachillerato) y otros tantos para el grado quadrivial o medio (licenciatura), que podía incorporar al profesorado (doctorado) con la aprobación de los colegas, la imposición de bonete y toga, y una lección pública. Eran estudios introductorios para abordar las facultades superiores: Derecho (romano y canónico), Medicina o Teología, que era en el sentir común la reina de las ciencias, duraderos otros seis o siete años con la misma gradación anterior. Pobrecitos estudiantes, más de una década doblando los codos, no es extraño que soñasen una compensación en su himno universitario gaudeamus igitur: "gocemos ahora que somos jóvenes". Se los apodó clérigos metonímicamente en cuanto enviados en gene-

${ }^{9}$ Suma teológica $\mathrm{I}, 1,2$. 
ral por la Iglesia, acertando todavía más en una segunda metonimia: goliardos ('gamberros'). Los maestros eran denominados lectores porque dictaban sus clases (lectiones).

La característica principal de las universidades fue cursar un clamor libertario: el cosmopolitismo, la facilidad de movimiento estudiantil; el democratismo, la elección de cargos y reglamento con los votos de profesores y estudiantes; y la autonomía de estudio y enseñanza, la libertad de la razón. Por ello no dejó de chocar con el Magisterio eclesiástico: el mismísimo papa deploró "lleno de la amargura del ajenjo" que los teólogos de París hicieran "ostentación de ciencia (...) obligando a la reina a servir a su esclava (...) al empeñarse en asentar la fe más de lo debido sobre la razón natural"10. En cualquier caso, el prestigio, influjo y desarrollo que propiciaban las universidades fomentó que ciudades y reinos las erigiesen como tesoros grupales. Hoy día seguimos nutridos por ellas.

Ciertamente, la teología escolástica, por su caldo académico, era muy racionalista. Tanto que algunos, como san Bernardo o san Buenaventura, sospechaban si con tanto razonamiento no se estaría arrinconando a la fe ${ }^{11}$. La revelación parecía casi una cuestión de demostración más que una llamada a la confianza en Dios. Las demostraciones teológicas (disputationes) seguían un estilo dialéctico, es decir, de discusión. Había que presentar las propias razones sobre cualquier tema para ser debatidas: en el aula, entre profesor y alumnos o alumnos entre sí; en las oposiciones a cátedra, entre los profesores que pretendían obtenerla; en los libros, que parecían adelantarse a posibles réplicas con capítulos que constaban de pros, contras y conclusiones. Se imponian los argumentos que resultaban mayoritariamente convincentes.

Una corriente de la teología escolástica fue el nominalismo. Compartiendo el mismo esquema especulativo o dialéctico de las universidades, desconfiaba del método deductivo basado en los conceptos generales, los universales, y prefería un sistema inductivo que partiera de las cosas, las percepciones sensibles. Quería cambiar el estilo de ciencia admitido hasta entonces, abstracto y de certezas teóricas, de principios evidentes por sí mismos, por otro más realista y concreto, más práctico. La revolución científica estaba a un pasito nada más...

${ }^{10} \mathrm{DH}$ 824. También a santo Tomás, pronto considerado el príncipe de los teólogos, le rozó la condena del obispo de París poco después de su muerte al ser rechazadas algunas ideas aristotélico-averroístas que había defendido.

11 "Su teología, por no decir estultología, considera la fe como una opinión" (SAN BERnARdo, Cartas 190,9). 


\section{Nietas engreídas}

Galileo Galilei es considerado el padre de la ciencia moderna, del saber cuantitativo y empírico, contrario al anterior tipo de ciencia cualitativa y esencialista. Estamos en la Modernidad renacentista, una época de cambios y alborotos por todas partes: el humanismo proclama la vuelta a la Edad Clásica, saltándose la que llama Edad Media; Lutero propone una religiosidad de fe individual, sin Iglesia; Descartes afirma que la filosofía debe proceder dudando de todo, particularmente de la tradición recibida; y Galileo pone en marcha la matematización de la física, esto es, que se comprueben concienzudamente las leyes naturales mediante la repetición experimental, y que luego se traduzcan a fórmulas matemáticas para que puedan ser fijadas, difundidas y reiteradas en cualquier lugar y momento.

Dejaron de valer sin más ni más, por las buenas, las autoridades antiguas, la mecánica aristotélica y sus axiomas autoevidentes: todo efecto tiene su causa, es decir, lo contingente proviene de lo necesario; el mundo supralunar es estático y por tanto perfecto mientras el terráqueo es cambiante y por ello imperfecto. Era necesario demostrar cada afirmación general, cada construcción teórica. Todo empezó con una ensoñación de Copérnico, al que le pareció que se predecirían mejor las posiciones planetarias partiendo de la centralidad del sol en vez de atribuírsela a la tierra...

Galileo comenzó probando pacientemente las leyes del movimiento y la inercia (la isocronía pendular que dará lugar a los relojes), de la caída libre de los objetos (de igual aceleración independientemente de su peso, que preanuncia la gravitación universal) y construyó un telescopio que zanjó la pretendida perfección celeste (montes lunares, manchas solares) y el sistema ptolemaico geocéntrico frente al copernicano heliocéntrico (los satélites de Júpiter no giraban en torno a la tierra, las fases de Venus se comprendían si éste orbitaba alrededor del sol). Todo ello derribó la física aristotélica de un manotazo, y por si fuera poco contradijo la física bíblica (Jos 10,12-14) conllevando las famosas condena eclesial por herejía y retractación suya preventiva. Pero la suerte estaba echada, todo empezó a explicarse bien de modo inmanente y empírico, "como si Dios no existiera"12.

12 La expresión procede del jurista coetáneo holandés Hugo Grocio (Derecho de guerra y paz, Prolegómenos 11) buscando una normativa de convivencia internacional que superase las disputas confesionales cristianas. Será popularizada en la interpretación del teólogo alemán Dietrich Bonhoeffer (Resistencia y sumisión, 16.VII.1944), considerando que el cristianismo debe acomodarse a un mundo sin fe. 
En el siglo XVIII Newton cuadró el movimiento de todas las cosas, la mecánica universal, una mezcla de inercia, gravedad y reacción que lo aclaraba todo, desde la simple caída de una manzana hasta las enigmáticas danzas astrales: de impulsión inercial indefinida, de traslación gravitatoria elíptica sobre un cuerpo mayor, de rotación sobre el propio eje, de precesión o bamboleo pendular... explicó los resortes del cosmos entero ¡con matemáticas! Qué cosas, vivir para ver. Al siglo XIX se le apareció Darwin simplificando la complejidad inasible de la biología: las variopintas variedades vivas, vegetales y animales, incluida la humana, procedían unas de otras, en el transcurso de millones de milenios, por adaptación entre casual y obligada a las circunstancias -principiando la fotosíntesis-, quién al agua generando branquias, quién al aire creando alas, quién a la tierra estirando patas, ¡quién al pensamiento agrandando el cerebro! Precisamente hurgar en el alma de modo empírico será la gloria de Freud en el siglo XX: de sus pacientes concluyó que la consciencia tiene mucho de inconsciente, un amasijo de instintos potentes (ello) apenas suavizados por la cultura (superyó) y las síntesis personales (yo), de cuya conflictiva relación irresuelta proceden las neurosis, enfermedades nerviosas que se traducen corporalmente como histerias y alergias, nos confunden con lapsus y pesadillas que queremos y no queremos, nos vuelven desconocidos ¡hasta para nosotros mismos!

Las añosas teología y filosofía fueron palideciendo ante la pujanza briosa de las nuevas ciencias experimentales, que faltándoles al respeto debido las denostaron como momias antediluvianas. Eran unas ciencias lozanas y exitosas, con el futuro por delante, pero mostraron tener mala memoria, ignorando desagradecidas que su ser se debía a los desvelos de sus progenitoras, a sus elucubraciones míticas cosmogónicas, sus hipótesis lógicas y atómicas, sus devaneos metafísicos y trascendentes. A la teología la fueron expulsando de la universidad, que ella había inspirado, tras la Ilustración y el secularismo, ¡pobre reina destronada! De la filosofía dijeron que si no sabe, mejor que se calle ${ }^{13}$. Menos mal que sabios piadosos decimonónicos retomaron el sentido más amplio de ciencia, saber comprobado colectivamente, para dividirla en ciencias naturales (escrutadoras de la naturaleza, de demostración empírica: física, química, biología...) y ciencias humanas (referidas a lo humano, de demostración lógica: filosofía, historia, sociología...). Pero a pesar de todo, las técnicas emanadas de las ciencias físicas, que tanto nos facilitaron y alargaron la vida (trenes, electricidad, medicinas, teléfono, automóviles, televisiones, ordenadores...) serán

${ }^{13}$ L. Wittgenstein, Tractatus logico-philosophicus 7. 
la puntilla de las ciencias metafísicas, arrojadas a un descrédito de inutilidad y vagancia que no merecen. ¡Como si pensar en la existencia y sus valores fuera algo superfluo!

\section{La bisnieta favorita}

La psicología nació como un híbrido de ciencias humanas y exactas, en dudosa decantación genética, una especie de filosofía empírica del alma, por imposible que suene. No hay más que mirar a su iniciador, en la segunda mitad del siglo XIX. El profesor alemán Wilhelm Wundt fue un médico de carrera devenido catedrático de filosofía; creó un laboratorio de psicología, curioso invento en el que sus alumnos medían sus sensaciones interiores al compás de un metrónomo: con los ojos cerrados y a la espera y resolución del cadencioso tictac experimentaban expectación-relajación, desagrado-agrado, impaciencia-tranquilidad; y a imitación de la química el sesudo doctor las juzgó los átomos mentales, los elementos básicos cuyas combinaciones generaban emociones y pensamientos.

Igualmente, no mucho después, el neurólogo Sigmund Freud resolvió curar extrañas enfermedades somáticas, que llamaban histerias -parálisis repentina de quien normalmente andaba o amnesia temporal de quien solía recordar-, ¡ charlando con los pacientes! El caso es que acertó -el subconsciente estaba velado en las palabras-y así surgió la psicoterapia: los hipnotizaba, les interpretaba los sueños, les cazaba gazapos significativos escuchando su verborrea... en suma, les sonsacaba el inconsciente para ponérselo delante y reconciliarlos con él. El inconsciente era un cuarto oscuro cerebral: albergaba pulsiones sexuales y destructivas que desde la infancia atormentaban al individuo, por lo que éste intentaba reprimirlas, pero sin lograrlo nunca del todo - no se puede suprimir la naturaleza, el deseo, el poder-, enloqueciéndole así más (psicosis) o menos (neurosis). La curación consistía en hacer conscientes dichas pulsiones, afrontar los propios fantasmas, reconocerlos, negociar con ellos... ¡Señoras y señores, queda inaugurado el psicoanálisis!

El triunfo del psicoanálisis le llenó la cabeza de pájaros, lo que se llama morir de éxito. Las ideas más absurdas las recomendaba como bálsamo de fierabrás, el subconsciente parecía una chistera de donde el analista sacaba toda clase de traumas como conejos desquiciados: interpretaciones oníricas que achicarían al mismísimo José de Egipto, matar al padre y acostarse con la madre como motores de la cultura (complejo de Edipo), constitutiva inferioridad femenina (envidia del pene)... Resultaba un trata- 
miento largo (años) y por tanto caro, subjetivo (demasiada hermenéutica profesional) y por tanto poco científico, pesado (una hora dos veces por semana) y por tanto aburrido (el paciente desbarraba en el diván mientras el analista cabeceaba tras él).

Pronto se desarrolló en Estados Unidos una corrección de la deriva psicoanalítica de la recién nacida ciencia. Consistía en atrapar el alma desde sus prolongaciones externas en el comportamiento: el conductismo. Era una auténtica ciencia experimental, la conducta se veía, se podían contar sus actos y repeticiones, se podían medir sus variaciones e intensidades. $\mathrm{Su}$ método curativo era forzar a cambiar las conductas raras, enfermas, para así transformar la morbosidad mental, como cuando uno silba en la oscuridad para tranquilizarse. Por ejemplo, si alguien tenía claustrofobia se le obligaba a entrar (poco a poco) en un ascensor para evidenciarle que podía sobrevivir (implosión), si alguien tenía aracnofobia se le presentaban juntas (pero no revueltas) una araña y su plato favorito de modo que la atracción sobrepujase la repulsión (contracondicionamiento). La psicología pareció entonces ser definitivamente una ciencia de la conducta. Pero el conductismo trascordó que si la acción influye en la mente, ésta también influye en aquélla, que hay que buscar las causas de la agorafobia o cualquier fobia para curarlas completamente, no basta arreglar los síntomas, un remedio solo superficial y temporal.

La psique no se moldea solamente por las condiciones externas, posee una infinitud interior, que nombramos espíritu: "por muchos caminos que recorras nunca hallarás los límites del alma"14. Una persona puede superar las presiones más extremas (la pobreza, la guerra, la pérdida...) si tiene carácter de hierro: "hay algo más poderoso que la energía atómica: la voluntad", dicen que dijo Einstein, que de lo primero sabía bastante. Puede sublimar los instintos biológicos más básicos (de sobrevivencia, de placer...) si le impulsa un altruismo invencible, si encuentra un sentido a su vida: "el que tiene un porqué soporta casi cualquier cómo"15. Se llamó a esta escuela psicología humanista, pues se centraba en las potencialidades propiamente humanas: el pensamiento y la libertad. Emparejaba lo mejor de las escuelas anteriores, la interioridad profunda del psicoanálisis y la determinación práctica del conductismo, desechando con cada una lo estrambótico de la otra, la arbitrariedad acientífica del primero y la ramplonería exteriorista del segundo.

\footnotetext{
${ }^{14}$ HERÁCLITO, Fragmentos 45.

15 V. FrANKL, El hombre en busca de sentido, Barcelona 1979, repite esta frase remitiéndola a Nietzsche.
} 
La psicología se volvió desde el principio tremendamente popular. Por una parte, poseía una accesibilidad universal: todo el mundo podía entenderla. No requería despejar ecuaciones matemáticas, no precisaba dominar fórmulas químicas ni combinaciones genéticas. Todos intuían bien, experimentaban, el significado de lo inconsciente, la frustración, el deseo, toda persona llevaba un psicólogo dentro como todos llevamos un seleccionador de fútbol dentro. Por otra parte, la psicología asumía una necesidad universal: conocerse a uno mismo. Ya avisaba el frontispicio del templo de Delfos que en eso estribaba la verdadera sabiduría. Comprenderse desde el interior era fortalecerse enteramente, comprender a los demás suponía hermanarse con ellos, la psicología conllevaba pues un instrumento de felicidad, justamente la meta de lo humano. Heredando el título regio antiguo de la teología, derrocada luego en la modernidad por las matemáticas, la psicología era aclamada ahora como la auténtica reina de las ciencias.

\section{Las recetas de la abuela}

Desde el primer momento la dedicación más común de la psicología fue la médica y los psicólogos más reputados, los psiquiatras. Aunque se la utilizara en pedagogía para optimizar los sistemas de enseñanza, en publicidad para idear técnicas de incitación al consumo, en política y empresas para identificar dotes de liderazgo... estaba claro que sus posibilidades más generales, fructíferas y solicitadas residirían en las aplicaciones clínicas, se captaba que la psicología curativa servía para todos: todo hombre se sabe imperfecto, lo que mentalmente puede llamarse neurótico, variando solo el grado o intensidad, así que bien podrá aprovechar los remedios psicológicos. El mundo está loco, solemos comentar, y nosotros dentro de él.

La variante psicológica humanista o cognitiva -basada en el pensamiento, a diferencia del psicoanálisis, abocado a lo emocional, y del conductismo, absorto en el comportamiento- ha advertido últimamente que la psicología ha sido demasiado negativa, esto es, se ha volcado preferentemente, si no exclusivamente, en la enfermedad anímica, en las distorsiones de la personalidad, las depresiones, hostilidades o ansiedades. Está bien que haya sido compasiva, o quizá mejor dicho interesada (la sanación da dinero y cuantos más locos mejor), pero ¿no debiera ser también positiva, entregarse igualmente a desarrollar las aptitudes humanas y no sólo a paliar fragilidades, a descubrir senderos de dicha y no sólo a vallar accesos al trastorno? Hay que distinguir bien la psicología positiva del llamado pensamiento positivo. Éste retiene un optimismo incondicional, no hace 
más que repetirse como un loro: 'todo va bien, todo va bien', aunque se tenga un cáncer de páncreas o se esté uno cociendo en la marmita de los caníbales. Aquélla equilibra un optimismo realista: aprovecha el sotavento en la brisa pero igualmente encara la zozobra de la mar arbolada (aunque naufrague), se alboroza si es guapa pero asume rabiosa ser fea (y tal vez se consuele con la belleza interior).

La psicología positiva intenta aguerrir el alma, y derivadamente también el cuerpo, pues como se sabe no hay dicotomía, mens sana in corpore insepulto, digo sano. Sería como la medicina preventiva, la de más vale prevenir que curar, que aconseja andar para evitar el colesterol y comer sin sal para aflojar la tensión arterial. Su meta declarada es que las personas se conozcan a sí mismas (como la sentencia délfica), que realcen sus capacidades (que llama virtudes) y persigan sus intereses (que sean asertivas), que sepan ayudar y dejarse ayudar (que tengan empatía), en suma, que estén contentas consigo mismas, relativamente satisfechas de su vida, que toquen la felicidad, pues atraparla es ilusorio. ¿No suena esto a antiguo, a las viejas teología y filosofía? Las grandes verdades son eternas, que dijo el sabio, pero nos parecen nuevas porque las olvidamos cada día. Así la psicología se topó con sus antepasados.

La teología cristiana podría resumirse en dos actitudes. Quizá suene excesivo decir esto de una religión tan densa en dogmas, liturgias, normas y estructuras. Pero es lo que comenta su fundador en el evangelio. "Los fariseos le preguntaron para ponerlo a prueba: ¿cuál es el mandamiento mayor de la Ley?" La Torah judía atropaba muchas leyes y costumbres, apelmazadas en el Pentateuco y el Talmud (tradición oral), así que era una cuestión de respuesta imposible, como preguntar a un catedrático de metafísica: 'en una palabra, ¿qué es el ser?'. Pero Jesús contestó con sencillez: "amarás al Señor tu Dios (...) y al prójimo como a ti mismo" (Mt 22,34ss).

Amar a Dios de corazón, con toda el alma, con todas las fuerzas, seguramente propone la confianza como modo de existencia. La vida es un don de Dios, un misterio de su generosidad, tiene pues que ser bella y maravillosa. Aunque también sea difícil y oscura tenemos que fiarnos de ese regalo, exprimir sus lados joviales y gozosos, blindar la esperanza a toda costa, a pesar de todo, a pesar de "la derrota que a todos nos ataca"16, a pesar de que a fin de cuentas termina mal, siempre nos acaba matando. Es la actitud mística, una afirmación de sentido, una percepción de Dios.

Amar al prójimo como a uno mismo invita a aceptar la evidencia: somos iguales, nacemos igualmente indefensos, vivimos igualmente anhe-

${ }^{16}$ L. CoHEn, Discurso premio Príncipe de Asturias, 21.X.2011. 
lantes, morimos igualmente forzados. Si la vida es lo único que tenemos, la vida es igualmente valiosa para todos, debiéramos aliarnos en su defensa. 'No hagas a los demás lo que no quieras que te hagan' es una regla de oro conocida desde la antigüedad oriental (también $\mathrm{Tb} 4,15$ ). "Todos vosotros sois hermanos", ratifica asimismo Jesús (Mt 23,8). Solos no podemos nada, nada en la infancia sin la familia, nada en la madurez sin la sociedad, nada en la vejez sin ambos, nada en el tiempo sin la humanidad. Es la actitud ética, una decisión de fraternidad, una trinchera de comunión.

Mística y ética están más imbricadas de lo que pueda pensarse, son como siamesas cerebrales, no se las puede separar sin herirlas mortalmente ¿Acaso es posible defender a un delincuente o apreciar a un pordiosero o asistir a un desagradecido sin cierto barrunto (místico viene de misterio) de que eso es lo correcto? Y al revés, ¿se puede mantener una existencia esperanzada $\sin$ la ejemplaridad emocionante de testimonios altruistas aunque vencidos (Jesús, Gandhi, Luther King...), "soldados derrotados de una causa invencible"17 que, según decimos, nos reconcilian con la vida?

\section{La última generación}

No es lo mismo conocer la receta del salmorejo que lograr hacerlo de rechupete, una cosa es ver a Arguiñano haciendo un pastel de verduras -trocea, pocha, rehoga, bate, hornea fácil ante las cámaras- y otra imitarlo sin que te salga un churro. Del dicho al hecho hay mucho trecho, no es lo mismo predicar que dar trigo, obras son amores y no buenas razones, las palabras se las lleva el viento... Nos toca, pues, asumir las enseñanzas antiguas tan claras, mimarlas como joyas de la corona, integrarlas en nuestro camino. ¿Pero cómo vivir esas nociones fundamentales, actuarlas en un mismo esfuerzo? Pues aunque no lo parezca, todos están de acuerdo; filosofía, teología y psicología responden: practicándolas. Además, las llaman del mismo modo: virtudes, energías internas para hacer lo que hay que hacer. Y además, por si fuera poco, las han concretado casi idénticamente.

Decía Aristóteles que la virtud no la da la naturaleza sino la costumbre, pues sólo "practicando la justicia nos hacemos justos; practicando la moderación, moderados; practicando el valor, valientes"18. San Pablo repi-

${ }^{17}$ Frase repetida por el obispo y poeta Casaldáliga (P.G. López BLANCO, Pedro, hombre: VV AA, Pedro Casaldáliga. Las causas que dan sentido a su vida. Retrato de una personalidad, Madrid 2009, 197).

18 Ética a Nicómaco 1103 a. 
te muchas veces que el ideal cristiano consiste en obrar unitariamente desde la fe, la esperanza y la caridad (por ejemplo 1Cor 13,13). Y la psicología positiva, tras repasar distintas tradiciones filosóficas y religiosas (de Buda a Tomás de Aquino, del judaísmo al islamismo) ha elencado las fortalezas básicas para sostener una vida feliz: sabiduría, valor, templanza, amor, justicia, trascendencia19. Efectivamente, están muy emparentadas con las virtudes capitales cristianas: humildad, paciencia y diligencia son variantes de la sabiduría y el valor; generosidad y caridad se insertan en la justicia y el amor; y la castidad es una concreción de la templanza. Las virtudes teologales de la fe y la esperanza estarían subsumidas en la trascendencia.

Los antiguos distinguían entre sabiduría y ciencia. Sabiduría es un saber existencial, moral, aprehender los valores de la vida; procede de sapere, 'saborear', gustar la realidad. Ciencia es un saber material, objetual, controlar los fenómenos de la naturaleza; viene de scire, 'separar', analizar las cosas. Por suerte, la sabiduría es accesible a todos, está hermanada con el sentido común, mientras la ciencia es propia de especialistas, calvos con gafas de culo de vaso. Por eso nuestros abuelos han podido ser tan felices como el que más, aunque no sabían ni les importaba si la tierra gira sobre su eje o las estrellas son fósiles de luz revenida. Sin embargo, la ciencia es necesaria como auxiliar de la sabiduría: entender que terremotos y volcanes provienen de roces tectónicos, o que inundaciones y huracanes se deben a desajustes climáticos, evita terrores a maldiciones divinas; el teléfono y los aviones nos permiten estar a tiro de piedra de seres queridos lejanos; y radiografías, escáneres, antibióticos y vacunas nos asisten en prevenir colapsos y ganar calidad de vida.

El valor es la entereza para afrontar la adversidad. Las contrariedades son algo consustancial a la existencia: sueños incumplidos y anhelos rotos, incomprensiones ajenas y amistades traicionadas, enfermedades multiformes y muerte final... ¿alguien da más? Siempre acompañan al hombre y no siempre se pueden dominar. Por eso el coraje es imprescindible. No trata de vencer la adversidad sino de arrostrarla, y en ello justamente consiste su superación. Unas veces los fantasmas desaparecen al mirarlos a los ojos (como el cuento indio del tigre sediento que se espantaba de su reflejo al pretender beber en un estanque cristalino; al decidirse y mojar la lengua, el espejismo se esfumó). Otras veces nos abate la frustración o la desdicha (la vida mata), pero la valentía sabe asumirlo para proseguir a pesar de todo. Nos caemos para aprender a levantarnos, que dijo el filósofo Bat-

${ }^{19}$ M. SELIGMAN, La auténtica felicidad, Barcelona 2003, 183s. 
$m a n^{20}$. El valor no es la ausencia de miedo, eso sería temeridad o ignorancia, sino la fuerza para remontarlo.

La templanza o austeridad no tiene buena prensa hoy día. Por algo campamos en una sociedad de consumo. Pero siendo el discernimiento de lo necesario, resulta insustituible para la vida dichosa o la dichosa vida. La carencia es mala, claro, pero la abundancia resulta todavía peor, porque es enervante, insaciable. El exceso sexual o gástrico es destructivo, crea obsesos y obesos. La riqueza desasosiega en la conciencia de su caducidad: se pierde, la roban, "cuando muera no se llevará nada" (Sal 49,18). Y la avaricia no descansa nunca, cuanto más tiene más quiere, supeditando todo lo demás: familia, amistad, salud, aficiones... precisamente lo más valioso. $\mathrm{O}$ sea, pone el mundo al revés. La sobriedad la encomiaba ya Epicuro, acusado injustamente de epicúreo: "nada es suficiente para quien lo suficiente es poco" 21 . Lo dice también, aunque de otro modo, el evangelio: "¿de qué le vale al hombre ganar el mundo entero si arruina su vida?" (Mc 8,36). A san Francisco le bastaba con los dones de la naturaleza, con "el hermano sol y la hermana luna", debe de ser un héroe tan popular porque contrarresta nuestra ansia constitutiva.

El amor y la justicia corren senderos complementarios, donde acaba uno empieza el otro; o quizá mejor superpuestos, no se sabe bien dónde subyace uno y aflora el otro. La justicia sin amor se muestra dura, a cara de perro, como partir al hijo de dos madres por la mitad (1Re 3,16ss), summun ius summa iniuria. Y el amor sin justicia es fatuo, quiere que se le agradezca eternamente lo que ha debido conceder hace tiempo, como la libertad a los esclavos o el sufragio a las mujeres en el pasado entresiglo. Lo mejor es armonizarlos, como dice hermosamente el salmista: "la justicia y el amor se besan" (Sal 85,11). Justicia es igualdad: ésta se intuye en lo esencial: nacemos, vivimos y morimos igual; por eso, aquélla intenta compensar lo que natura y cultura desigualan: salud y educación, amparo y oportunidad para todos. Amor es generosidad: por un lado, donación de lo excedente (socorre a damnificados por guerras o cataclismos, no abandona a vagabundos y delincuentes), confiesa que seguimos siendo iguales levantando a los rebajados por la desgracia o sus malas decisiones, hoy por ti, mañana por mí; por otro lado es donación de sí (apertura a los demás, comunicación de uno mismo, solidaridad con todos) simplemente porque somos semejantes, coexistentes, hermanos. Ser rico, listo y guapo es una

${ }^{20}$ Batman begins, Christopher Nolan, 2005. Máxima atribuida originalmente a Confucio.

21 Sentencias 68. 
lotería, agradecidos deberían sentirse ellos y ser dadivosos con los menos afortunados. El amor comprende que hay que ir un poco más allá de la justicia, que no todo se arregla con leyes y protocolos, "la misericordia supera al juicio" (St 2,13).

Resulta curioso ver la trascendencia entre las virtudes civiles, siendo elemental como virtud religiosa, pero es compaginable su interpretación en ambas listas, no es discordante en su idiosincrasia particular. Sería en todo caso la disposición a lo más allá de lo sensible, la aceptación del enigma que es el mundo y la existencia. Es al tiempo flotar entre la búsqueda de sentido y la acogida del misterio, no saber y saber, dependencia y libertad. La vida nos es entregada sin pedirnos permiso, pero queda luego a nuestro albedrío, "el destino baraja las cartas y nosotros las jugamos"22. Es como un regalo que podemos emplear o arrumbar, tener en uso sobre la cómoda o el armario u olvidar en el cajón o el desván. Trascendencia es siempre confianza y esperanza, recaiga en Dios o la humanidad, se adense como respeto al prójimo o dedicación a la familia.

Podría haber otras virtudes, hasta ahora no tenidas como tales, pero igualmente preciosas para una vida lograda. Por ejemplo, la identidad, la captación de sí como único, ser consciente de la belleza y el dolor de lo a la vez irrepetible y caduco. Se ejercitaría con la soledad y la meditación, apestadas socialmente hoy día como leprosas. O por ejemplo, el humor, saber relativizarlo todo, incluido ese saber, porque todo es ambiguo, insuficiente, menos la vida misma, nuestro único absoluto (sic) (Dar o arriesgar la vida por otros valores, como la libertad o la fraternidad, requiere por eso una grandeza de ánimo muy especial) (sic). El reflejo serio del humor es la tolerancia, que no significa que todo vale sino que todo es digno de consideración, salvo la destrucción de la vida. En fin, quizá estas virtudes formen parte de la sabiduría y no necesiten mención aparte.

\section{¿Qué familia!}

La filosofía griega nació interrogándose sobre "aquello de lo que están constituidas todas las cosas" 23 , la teología cristiana oteaba que todo se resumía en "conocer a Dios y el alma" 24 , el racionalismo moderno lo redondeó con la pregunta: “¿por qué existe algo y no más bien nada?”25, y

22 A. SChOPenhaUer, Parerga y paralipómena 1, Aforismos 5,48.

${ }^{23}$ ARISTÓTELes, Metafísica $983 \mathrm{~b}$.

24 SAN Agustín, Soliloquios 1,7.

25 G.W. LeIBNIZ, Principios de naturaleza y gracia 7. 
la ciencia actual asciende sobre tres escalones en el aire, milagros más allá de nuestra capacidad: "el origen del universo, el origen de la vida, el origen de la conciencia"26. En el fondo, y casi en la forma, son la misma cuestión irresuelta: el porqué y para qué de todo, la fuente y la meta de la realidad. Todos los saberes y artes merodean en torno a este asunto, desde la mitología a la física cuántica, pasando por el teatro, la fotografía o la quiropraxia.

La teología siempre lo ha tenido claro: "en el principio creó Dios el cielo y la tierra", comienza diciendo la Biblia; "en el principio existía el Lógos (...) y el Lógos era Dios”, replica el prólogo joánico. El Lógos sería algo así como el todo racional, lo que la filosofía clásica denominaba el ser. Vuelve a ponerse en evidencia su parentesco: una cree en el sentido absoluto, trascendente y personal de todo, la otra confía más modestamente en la inteligibilidad inmanente de las cosas, sin atreverse a más. ¿Y qué decir de sus hijas? La física aborda recomponer el rompecabezas que es la naturaleza, sobre todo para saber qué lugar ocupamos dentro de él. De la historia se dice que es "maestra de la vida" 27 , pues pretende que escarmentemos en el futuro a la hora de actuar colectivamente. De igual modo, la ética quiere iluminar el comportamiento correcto basada en la experiencia común (éthos, 'costumbre'). La literatura o la escultura o la música se devanan a su vez en ordenar mediante ficciones o creaciones el caos de la existencia, de modo que puedan servir para aplicarnos el cuento, sugerirnos emociones y soluciones, exorcizar nuestros demonios. Verdaderamente todas las ciencias y artes persiguen saber para poder... ayudar a prever, a vivir, a ser felices, el horizonte común de la humanidad.

Aprender del saber antiguo pretende ahorrarnos esfuerzo, evitar andar constantemente un camino ya andado: el filósofo griego Aristarco ya propuso el heliocentrismo en el siglo III aC, pero tuvo que transcurrir más de un milenio para retomar su punto de partida. ¡Vaya despilfarro de siglos! Progresamos a partir de lo que la tradición nos ha legado, no es posible la actual comunicación audiovisual sin las ondas satelitales, a su vez inabordables sin la mecánica relativista y cuántica, que se impulsan desde la gravedad newtoniana, de su parte inviable sin el heliocentrismo copernicano, que ya Aristarco había intuido... Por otra parte, la cultura nos permite encuadrar e interpretar hechos que de otro modo se nos escaparían, seríamos como niños que se preguntan por qué la luna no se cae o a las vacas les llegan las patas al suelo o si el hombre viene del mono porque la mujer

$26 \mathrm{~K}$. POPPER, El universo abierto. Un argumento en favor del indeterminismo, Madrid 1984, 144.

27 CiCERón, El orador 2,9,36. 
es mona. El universo es demasiado grande y complejo (tal vez infinito) para una pobre época humana.

Todas las ciencias son parientes, lo dice su genoma humanista, no debieran pues echarse los trastos a la cabeza, las exactas acusando a las sociales de fantasiosas y éstas tachando a aquéllas de crematísticas. Están condenadas a colaborar entre sí, la sangre es lo que tiene. De hecho, cada panda suele utilizar técnicas exitosas de la otra, la sociología tiene que emplear la matemática (estadística) como la biología no puede prescindir de la lingüística (terminológica y clasificatoria) o la medicina se extravía sin la ética (¿eutanasia o encarnizamiento terapéutico, aborto o fecundación artificial?).

La joven psicología creció para ayudar al hombre a aceptar sus límites (tolerancia a la frustración), convivir con sus semejantes (empatía) y explorar sus posibilidades (autorrealización), a ser al tiempo realista, solidario y feliz. La vieja teología siempre pretendió auxiliar a los humanos para encontrar una explicación al mundo (creación divina), para aceptar la necesidad de los demás (fraternidad), para resistir el acoso de la muerte (imagen de Dios), para expresar, compartir y dar un sentido a la existencia. La comparación entre psicólogos y sacerdotes ha sido espontánea y corriente desde el primer instante, consultorías y confesionarios, terapias y dirección espiritual se parecen como dos gotas de agua, son las caras laica y religiosa de la misma moneda anímica. Ciertamente teología y psicología resultan consanguíneas por línea directa mediante la filosofía a la vez imaginativa (racionalismo) y prosaica (empirismo). Haya paz y colaboración, consuenan en rasgos y destino, ambición y pequeñez. 